\title{
Os nomes da língua: configuração e desdobramentos do debate sobre a língua brasileira no século XIX
}

\author{
Olga Ferreira Coelho ${ }^{1}$
}

\section{Resumo}

No século XIX, a determinação do grau de autonomia da modalidade de língua portuguesa utilizada no Brasil foi tema de calorosas e recorrentes discussões. Intelectuais de diferentes especialidades nascentes mobilizaram-se em torno desse assunto e contribuíram para que ele se mantivesse em evidência até, pelo menos, as quatro primeiras décadas do século XX. Neste artigo, valendo-nos, sobretudo, dos trabalhos de Rubim (1853), Beaurepaire-Rohan (1888) e Macedo Soares (1875/1889 e 1874/1891) - dedicados à compilação e à descrição do léxico específico do português do Brasil -, acompanhamos esse debate, procurando avaliar implicações que o privilégio da dimensão vocabular da língua trouxe para a discussão e para certas práticas de tratamento da linguagem que começaram a se articular no país a partir dos anos 1800.

\section{Palavras-chave}

português do Brasil; léxico; século XIX; historiografia lingüística.

1 Professora do Departamento de Lingüística e pesquisadora do Centro de Documentação em Historiografia Lingüística (Cedoch) da Faculdade de Filosofia, Letras e Ciências Humanas da Universidade de São Paulo.

E-mail: olgafc@usp.br 


\title{
The names of the language: setting and developments of the debate on the Brazilian language in the XIXth century
}

\author{
Olga Ferreira Coelho
}

\begin{abstract}
In the XIXth century, the resolution on the degree of authonomy of the Portuguese language modality used in Brazil was the subject of vigorous and recurrent discussions. Intellectuals coming from different emerging fields gathered this subject and contributed to keep it on the agenda, at least, the four first decades of the XXth century. In this paper, mainly based on the works of Rubim 1853, Beaurepaire-Rohan 1888 and Macedo Soares 1875/1889 and 1874/1891 - dedicated to the compilation and description of the specific lexicon of Brazilian Portuguese -, we follow this debate, in the attempt of evaluating implications that the privilege of the lexical dimension of the language brought to the discussion and to certain linguistic practices which started in the country in the 1800s.
\end{abstract}

Keywords

Brazilian Portuguese; lexicon; XIXth century; linguistic historiography. 


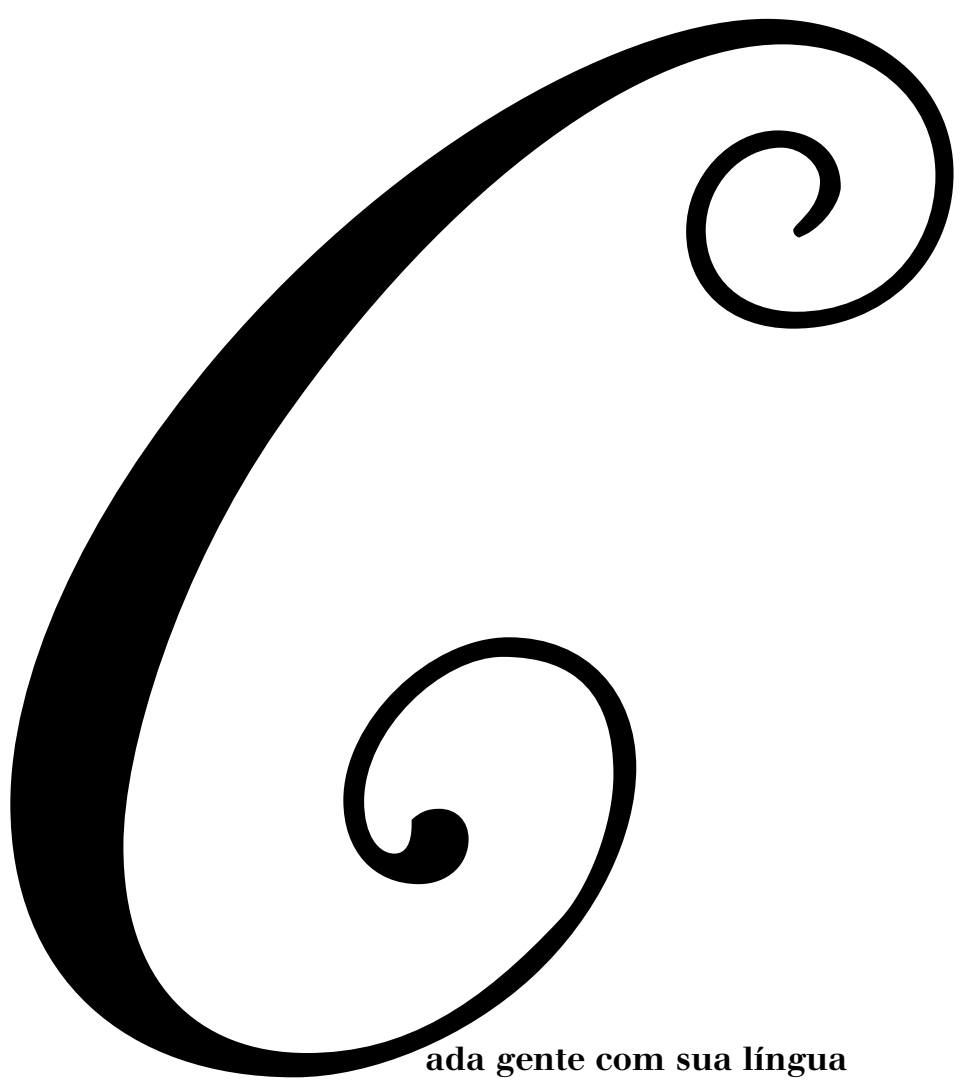

Em seu Catálogo de las lenguas de las naciones conocidas (1800/ 1805)², Lorenzo Hervás (1735-1809) estabeleceu um conjunto de critérios que considerou adequados para a caracterização e a classificação de todas as línguas existentes. Sua finalidade era, a partir de estudos lingüísticos, reunir elementos que permitissem agrupar as nações em diferentes famílias. É possível, em vista disso, enxergar em sua obra monumental uma equação segundo a qual a cada língua corresponderia uma nação.

Em codificações menos fortes e explícitas, essa equação encontrou espaço em diferentes trabalhos, de diferentes períodos, especialmente naqueles em que foram descritos os primeiros estágios do processo de consolidação das chamadas línguas nacionais. Por mais próximas que fossem as línguas, cada uma delas teria suas particularidades, suas marcas; e ressaltar seus atributos corresponderia a enaltecer qualidades da própria gente que a empregava, já que as características definidoras dos povos se espelhariam em seus falares. É assim que encontramos índices da equivalência

2 HERVÁS Y PANDURO, Lorenzo. Catálogo de las lenguas de las naciones conocidas, y numeración, división, y clases de estas segun la diversidad de sus idiomas y dialectos. Madrid: Imprenta de la Administración de Beneficiencia, 1800/1805.

I 4 I

revista ieb $n_{47}$ setembro de 2008 
proposta por Hervás ao observarmos, por exemplo, o caso de Portugal no século XVI, momento em que ocorre a primeira sistematização da gramática da língua portuguesa: parecia necessário individualizar dicções, sentidos, estruturas típicas daquele idioma e, com isso, apontar traços particulares também do povo que o utilizava. Não é, pois, surpreendente, que localizemos em Fernão d'Oliveira (1531-1580/81), o primeiro gramático, trechos como os seguintes:

[...] umas gentes formam suas vozes mais no papo, como Caldeus e Arábicos, e outras nações cortam vozes, apressando-se mais em seu falar, mas nós falamos com grande repouso, como homens assentados.

[...] Os Gregos com os Latinos e os Hebraicos com os Arábicos e nós com os Castelhanos, que somos mais vizinhos, concorremos muitas vezes em umas vozes e letras e contudo não tanto que não fique alguma particularidade a cada um por si [...]. E no pronunciar quem não sentirá a diferença que temos porque eles escondem-se e nós abrimos mais a boca? E quase podemos dizer que o que dá a entender Horácio na Arte Poética dos Gregos e Latinos temos entre nós e os Castelhanos porque a eles deu a natureza afeiçoar o que querem dizer e nós falamos com mais majestade e firmeza. ${ }^{3}$

Debates acerca das chamadas línguas nacionais são uma espécie de lugar-comum nos momentos em que há alguma (re)definição do estatuto político dos povos - o que torna o século XIX um período especialmente rico para o tratamento desse tema na América. Notamos, com efeito, em obras produzidas em países americanos que se tornaram independentes à época, uma busca reiterada de aspectos lingüísticos que contribuíssem para o delineamento de um quadro político ainda em formação. E o Brasil não escapou a essa tendência: nos anos 1800, o grau de autonomia da modalidade de língua portuguesa utilizada no país foi tema de calorosas e recorrentes discussões. A língua nacional converteu-se em um dos focos de maior mobilização de intelectuais - das mais diversas especialidades nascentes em torno das questões de linguagem. Perpassando de estudos estritamente lingüísticos a textos literários, etnográficos, históricos, folclóricos, projetos políticos, o assunto esteve em evidência e sua discussão se manteve bastante aquecida até, pelo menos, as quatro primeiras décadas do século $\mathrm{XX}^{4}$.

3 OLIVEIRA, Fernão d'. Gramática da linguagem portuguesa. $2^{\mathrm{a}}$. ed. Lisboa: Biblioteca Nacional, 1988[1536], p. 39 e p.47-48, respectivamente.

4 Cf. ELIA, Sílvio Edmundo. O problema da língua brasileira. $2^{\text {a }}$. ed. Rio de Janeiro: Irmãos Pongetti Editores, 1961[1940]; PINTO, Edith Pimentel. O português do Brasil. Textos críticos e teóricos. Fontes para a teoria e a história (1820-1920). vol. I. Rio de 
O português do Brasil, ora tomado como autônomo, ora como mera variante diatópica da língua de Portugal, foi avaliado, no contexto dessas discussões, fundamentalmente em sua dimensão vocabular.

O privilégio do léxico nessa contenda ensejou, entre as décadas de 1850 e 1890, a publicação de obras especificamente voltadas para essa dimensão da língua. Tais obras tanto correspondem a sínteses gerais - como o Vocabulário brasileiro para servir de complemento aos dicionários da língua portuguesa $^{5}$, de Brás da Costa Rubim (1817-1871), o Diccionario brazileiro da língua portuguesa ${ }^{6}$, de Antônio Joaquim de Macedo Soares (1838-1905), e o Dicionário de vocábulos brazileiros $^{7}$, do Visconde Henrique de Beaurepaire-Rohan (1812-1894) -, quanto a produções voltadas para particularidades regionais.

Dessas últimas, são exemplos o Vocabulário indigena de uso na província do Ceará, com explicações etymologicas, orthographicas, topographicas, históricas ${ }^{8}$, de Paulino Nogueira, o Vocabulário sul-riograndense ${ }^{9}$, de Romaguera J. Correa, e a Colleccão de vocábulos e phrases usados na província de São Pedro do Rio Grande do Sul ${ }^{10}$, de Antônio Álvares Pereira

Janeiro: Livros Técnicos e Científicos, 1978; ORLANDI, Eni (Org.). Discurso fundador. A formação do país e a construção da identidade nacional. Campinas: Pontes, 1993; DIAS, Luiz Francisco. Os sentidos do idioma nacional. As bases enunciativas do nacionalismo lingüístico no Brasil. Campinas: Pontes, 1996; CHRISTINO, Beatriz \& COELHO, Olga. O tratamento da diversidade lingüística. O século XIX. In ALTMAN, C. \& IMAGUIRE, L. As línguas do Brasil. Tipos, variedades regionais e modalidades discursivas. São Paulo: Humanitas, 2000. p. 191-197. O texto de Pinto corresponde à mais completa organização de fontes para a historiografia lingüística do tema no Brasil. A diversidade de materiais e autores reunidos no volume I (1820-1920) dão a medida de sua recorrência e relevância no século XIX. O texto de Elia reconstitui a discussão, dos anos 1820 até trabalhos do início do século XX (na $2^{\mathrm{a}}$. edição, de 1961) com vistas à comprovação da premissa de que a língua utilizada no Brasil é a mesma língua portuguesa usada em Portugal, ainda que possua "estilo" diferente. O trabalho de Dias, centrado nas décadas de 1930 e 1940, remete o leitor à década de 1820, quando projetos que requisitavam diplomas médicos emitidos em "língua brasileira" (1826) e ensino da gramática da "língua nacional" (1827) iniciaram o debate na esfera legislativa. Christino e Coelho traçam um panorama não exaustivo das formas de tratamento do tema entre as três últimas décadas do século XIX e a primeira do XX; Orlandi analisa as configurações discursivas e ideológicas desse debate e seu impacto na constituição de uma identidade nacional.

5 RUBIM, Braz da Costa. Vocabulário brasileiro para servir de complemento aos dicionários da língua portuguesa. Rio de Janeiro: Dous de Dezembro, 1853.

6 MACEDO SOARES, Antônio Joaquim de. Diccionario Brazileiro da língua portuguesa. Rio de Janeiro: Typ. De G. Leuzinger \& Filhos. 1889 [1875/1888].

7 BEAUREPAIRE-ROHAN, Henrique Pedro Carlos de. Dicionário de vocábulos brasileiros. $2^{\mathrm{a}}$. ed. [Fac-similada]. Salvador: Livraria Progresso, 1956 [1889].

8 NOGUEIRA, Paulino. Vocabulário indígena de uso na província do Ceará, com explicações etymologicas, orthographicas, topographicas, históricas. Ceará: s. n., 1887.

9 CORREA, Romaguera J. Vocabulário sul-riograndense. S.L: Fchenique \& Irmão, 1897.

10 CORUJA, Antônio Álvares Pereira. Collecção de vocábulos e phrases usados na província de São Pedro do Rio Grande do Sul Revista do IHGB, Rio de Janeiro, Tomo XV, p. 210-240, 1852. 
Coruja (1806-1889), texto mais recorrentemente lembrado em retrospectivas históricas do período. A esses dois tipos de textos, de natureza mais descritiva e técnica, juntam-se, no mesmo período, artigos e outros trabalhos, de vocação mais reflexiva, publicados por Macedo Soares e reunidos, postumamente, no volume Estudos lexicográficos do dialeto brasileiro ${ }^{11}$.

A eleição do léxico como principal fornecedor de argumentos parece ter conferido às obras dedicadas à defesa da autonomia lingüística certa ambigüidade, que, por sua vez, redundou no enfraquecimento paulatino dessa tese e no delineamento de algumas características definidoras das práticas preferenciais de tratamento da linguagem posteriormente desenvolvidas no país.

Observaremos esse debate mais de perto, a fim de avaliar essas hipóteses. Os textos de Rubim, Beaurepaire-Rohan e Macedo Soares merecerão nossa análise mais atenta.

\section{Os lexicógrafos do português do Brasil}

Com pequenas alterações, Morais e Aulete, os dois dicionários de língua portuguesa mais prestigiados durante o século XIX e o início do XX no Brasil, definem nação como "gente de um paiz, região, que tem Língua, Leis e Governo à parte" ${ }^{\prime 2}$. Ao menos no dicionário, ser uma nação significava possuir autonomia política, administrativa e lingüística. No momento em que surge a produção lexicográfica analisada - o Segundo Reinado (1840-1889) - já havia leis próprias e um governo, finalmente, brasileiro. O período era propício, pois, à análise cuidadosa da questão da língua, que emergia em meio a uma série de mudanças que reorganizavam aspectos da estrutura e da imagem do Império.

Para Guimarães ${ }^{15}$, o que se nota, nessa época, é a consecução de um certo projeto de Brasil: depois de implantado o Estado Nacional, impunha-se como tarefa o desenho de um perfil para essa nação, "capaz de lhe garantir uma identidade própria no conjunto mais amplo das 'Nações', de acordo com os novos princípios organizadores da vida social do século XIX" ${ }^{\prime 14}$. Como

11 MACEDO SOARES, Antônio Joaquim de. Estudos lexicográficos do dialeto brasileiro. [Org. Julião Rangel de Macedo Soares]. Rio de Janeiro: Publicação da Revista do IHGB, 1942 [1874/1891].

12 SILVA, Antonio de Morais. Diccionário da língua portuguesa. $2^{\mathrm{a}}$. ed. Rio de Janeiro: Empresa Literária, 1813 [1789].

13 GUIMARÃES, Manoel Luís Salgado. Nação e civilização nos trópicos. O Instituto Histórico e Geográfico Brasileiro e o projeto de uma história nacional. Estudos Históricos. 1, p. 5-22, 1988.

14 Ibidem. p.8. 
o espelho eram os Estados Europeus, se tal projeto deveria assegurar particularidades, deveria também, e sobretudo, garantir a inserção do país no conjunto dos que se tinham por civilizados.

O Instituto Histórico e Geográfico Brasileiro (IHGB) assumiria parte significativa dessa tarefa: deveria coletar, catalogar, publicar ou depositar em arquivos documentos relativos à história e à geografia do Brasil; promover o conhecimento desses dois segmentos da ciência; manter-se em contato com associações similares do Velho e do Novo Mundo; promover a integração das províncias para melhor atingir os objetivos propostos, e publicar uma revista ${ }^{15}$.

Beaurepaire-Rohan e Rubim pertenceram a essa agremiação; o primeiro chegou a ocupar o posto de vice-presidente do instituto. A viabilização de um projeto nacional aparece, pois, como um importante cenário para a sua produção intelectual. É de fato altamente provável que, em face dessa circunstância, a língua tenha sido entendida por eles não como um objeto autônomo, mas como uma das peças importantes na concretização de um plano mais abrangente, de reconhecimento do Brasil e de fixação de seu perfil.

Oficialmente, as questões propriamente lingüísticas passaram a integrar as preocupações dos intelectuais do IHGB apenas a partir de 1851, quando reformulações estatutárias recomendaram o desenvolvimento de estudos etnográficos, arqueológicos e relativos às línguas, principalmente as dos indígenas brasileiros. Sintomaticamente, a Collecção de vocábulos e phrases usados na província de São Pedro do Rio Grande do Sul, de Coruja, ganha as páginas da revista do IHGB em 1852. No ano seguinte, Rubim publica seu Vocabulário brazileiro.

Aparentemente, Rubim sentia-se o menos apto, dentre os três autores destacados neste artigo, para discorrer sobre a língua do Brasil. Alegava não ser especialista. Nessa condição, organizou um estudo bastante breve, com grande proporção de termos relativos à flora (campo do qual declarava conhecimento), meramente classificados segundo a taxionomia proposta pelas ciências biológicas. Constantemente, e talvez em função de seu caráter panorâmico, esse vocabulário é esquecido em retrospectivas históricas do período.

Beaurepaire-Rohan, por outro lado, é autor de um festejado dicionário do português do Brasil. A rigor, no período que destacamos, seu dicionário é o único inteiramente dedicado a esse corpus - já que Rubim propõe um vocabulário e o dicionário de Macedo Soares, interrompido, estende-se apenas até a letra $c$.

$15 C f$. Revista do IHGB I, 1839, 1:4-10.

I45 revista ieb $n_{47}$ setembro de 2008 
Autor da Carta geográfica do Império (1883), Beaurepaire-Rohan realizou, a serviço do Estado, viagens exploratórias pelas províncias do Pará, Ceará, Paraná, Rio Grande do Sul, da Paraíba, da Bahia, de Pernambuco e de Santa Catarina. Em muitas delas, exerceu funções administrativas de destaque. Obteve, em virtude de sua permanência em distintas regiões do país, a fama de conhecedor profundo do mosaico lingüístico nacional. Estava, assim, habilitado a versar sobre as peculiaridades culturais e vocabulares das diferentes províncias ${ }^{16}$. Seu dicionário é, com efeito, largamente detalhado em relação à distribuição geográfica dos itens lexicais ali registrados: assim como as paisagens diversificavam-se, a língua assumia matizes distintos ao longo de um país com dimensões continentais. E tal diversidade poderia ser mapeada em um dicionário de vocábulos locais.

Na produção lexicográfica do período, o regional tende, com efeito, a ser tomado como exemplo da amplitude da linguagem nacional. É, nesse sentido, paradoxal que a diversidade lingüística entre esta nação e a portuguesa tenha sido usada como argumento pró-autonomia, enquanto a diversidade interna ao Brasil tenha servido apenas para ilustrar a complexidade e a riqueza do falar local. Não se explicam os critérios adotados, fica somente declarado que a diferença entre mandioca e aipim, por exemplo, é interna ao português do Brasil e se estabelece entre unidades pertencentes à mesma língua, ao passo que a verificada entre fósforos e lumes promptos sinaliza a existência de dois sistemas lingüísticos já não idênticos ${ }^{17}$.

Os textos produzidos pelos lexicógrafos do IHGB guardam, contudo, menores excessos patrióticos no momento de assinalar distinções entre o português do Brasil e o de Portugal. A idéia de uma linguagem específica, antes formulada como defesa de um vocabulário exclusivo do Brasil, não os leva a críticas agressivas a Portugal ou à língua portuguesa - procedimento comum em Macedo Soares, advogado e literato que abertamente reivindicou autonomia, prestígio e superioridade para a linguagem do Brasil:

Mais dia, menos dia, [os críticos de Lisboa] vão ser forçados a fazer duas confissões importantes: a 1. é que no Brasil a língua portuguesa tem sido menos atacada do gálico, que a está corroendo e deformando em Portugal; a 2. é que temos uma língua nossa, e, portanto, uma literatura nossa... ${ }^{18}$

16 Cf. COELHO, Olga Ferreira. A anguzada lexicográfica luso-bundo-brasileira. Língua e identidade nacional na segunda metade do século XIX. 2003. Tese (Doutorado em Lingüística). DL, FFLCH-USP, 2003.

$17 C f$. CHRISTINO, Beatriz \& COELHO, Olga. Op. cit.; COELHO, Olga Ferreira. Op. cit.

$18 C f$. MACEDO SOARES, Antônio Joaquim de. Chapada, chapadão, chato, loma, planiço, varge. In: Estudos lexicográficos do dialeto brasileiro. Op. cit. p. 87. 
Para o autor, pontuar as divergências entre a língua do Brasil e a de Portugal, certamente menos pura e menos conservadora, levaria ao inevitável reconhecimento das produções literárias locais. O pressuposto era que, para uma literatura ser reconhecida, deveria ser veiculada em idioma de cultura. Portanto, não era possível aceitar que o português do Brasil continuasse a ser considerado como corrupção do português da Europa. Legitimar a língua do Brasil significava tornar sua literatura digna. $O$ raciocínio inverso também era válido e ampliava os efeitos do ato de descrever e analisar o brasileiro: à medida que a língua, tachada pelos portugueses de incorreta, ganhasse os textos literários, receberia o predicado de civilizada, e este poderia ser estendido à nação. Era necessário, portanto, imprimir à alegada língua inculta do Brasil "o cunho dos idiomas literários”, dar-lhe "foros de cidade" ${ }^{19}$, para que pudesse exemplificar a pujança do estado que a abrigava. $\mathrm{O}$ autor pretendia que certas peculiaridades da linguagem nacional pudessem também ter o estatuto de norma culta. Para tanto, reiteradamente evocava semelhanças dessa linguagem com o português mais antigo e imaculado:

Os nossos jornalistas escrevem muito diverso do que falam. Falando, dizem que moram na rua do Ouvidor, no largo da Lapa, no campo de Santa Anna, nas Laranjeiras; escrevendo, dizem que moram às Laranjeiras, ao campo de Santa Anna, à rua do Ouvidor, ao largo da Lapa. Falando, são brasileiros, ainda lembrados do bom português de Camões, fr. Luiz de Souza, de Vieira, das ordenações do reino, de todos os antigos monumentos do bem falar lusitano, que ficou na colônia da América. Escrevendo, teem um medo que se pelam das risotas do Chiado, e tratam de acompanhar os jornalistas de Lisboa, que quase se envergonham de ser portugueses, e por isso mesclam de francês e mais estrangeirices a língua que de seus pais herdaram. ${ }^{20}$

Contra o purismo português, o forjamento de legitimidade para a variante local através da arte e também da escrita comum (jornalística):

..."Virge Maria!" Exclamação de susto, de medo, de admiração, de alegria [...]; e havemos de reparar que não é só dos lábios da gente rude que ela escapa... E quando fosse, do vulgacho vai passando para o povo, e do povo para os letrados, porque estes se formam na

19 Idem. Baptista Caetano. Homenagem do discípulo. In: Estudos lexicográficos do dialeto brasileiro. Op. cit. p. 14.

$20 C f$. Idem. Estadoal, estadual, estatual? In: Estudos lexicográficos do dialeto brasileiro. Op. cit. p. 202. 
imprensa jornalística, e o jornal é o grande livro onde o povo cada dia escreve, a tribuna donde cada dia fala a linguagem que é sua, e fica sendo a linguagem nacional. ${ }^{21}$

A visão de que o jornalismo e o jornal tinham um papel na conformação da língua é original no período. As autoridades da escrita eram, conforme a tradição, os literatos. No entanto, Macedo Soares faz a linguagem literária - presumivelmente mais trabalhada, elaborada - ladear a linguagem popular, por definição mais espontânea. Principalmente, prevê que, pelo uso, vulgaridades poderiam perder o valor negativo e tornarem-se comuns. É esse o julgamento que faz, por exemplo, de palavras e expressões populares, como Virge Maria!, mas também de palavras como bunda:

BUNDA $s f$., o assento, as nádegas, onde se bate; que bate. ETYM. Bd. Cu-bunda. LEX PORT. Aul.[ete] def.[ine]: "t.[ermo] Braz[ileiro]. Nádegas volumosas". Beaurepaire Rohan o confirma; o adj.[etivo], porém, é de mais: carnudas ou magras, as nádegas são sempre bunda, pal.[alvra] chula para os ports.[portugueses], mas pop.[popular] no Brazil, e por isso muito acceitável. ${ }^{22}$

Como é notório, além de idéias inovadoras para o período, esse autor utiliza-se de estilo mais agressivo no apontamento de divergências entre Brasil e Portugal. Menos comprometidos com o saber oficial e com a política de manutenção de um contato cordial com os portugueses, seus textos não poupam críticas aos colonizadores, a sua literatura e a sua língua. Em certas passagens, o tratamento de questões vocabulares converte-se em guerra retórica. Os dados lingüísticos nesses instantes são o pretexto para desenvolverem-se outros tipos de disputas:

CABRA s.2, adj.2 - 1) quarteirão de mulato com negro; mulato escuro; caboclo escuro [...] era nesse sentido que os portugueses, nas lutas da nossa independência, parodiavam a quadrinha do nosso hino Brava gente brasileira, desta sorte "cabra gente brasileira/descendentes de Guiné/ Trocaram as cinco chagas/ pelo fumo e o café [...]”. Esqueciam-se que eles primeiro se amulataram em Angola do que no Brasil. ${ }^{23}$

A citação certamente deixa entrever restrições étnicas muito difundidas no período e, principalmente, ilustra os tipos de provocações que se faziam de parte a parte.

21 Idem. Estudos lexicográficos do dialeto brasileiro. Op. cit. p. 91.

22 Idem. Diccionario brazileiro da língua portuguesa. Op. cit. p. 114.

23 Idem. Estudos lexicográficos do dialeto brasileiro. Op. cit. p. 120. 
Essa espécie de repúdio a Portugal apresenta também nuanças mais técnicas, como a do descrédito atribuído à tradição portuguesa de estudos da língua:

É curiosa a descrição que dão de capoeira os léxicos portugueses, demonstrando ainda uma vez que a língua brasileira já é alguma coisa diferente da portuguesa, como não podia deixar de ser, atentos os elementos que, desde as primeiras povoações do Brasil, estão influindo para esse resultado. Frei Domingos Vieira, depois de definir capoeira como o negro que vive no mato e acomete os passageiros à faca [!] dá capoeirão o que tem vivido muito na capoeira [!].

Constâncio é ainda mais engraçado na origem da palavra: capoeira tira o nome de ser matagal de arbustos semelhantes aos de que se fazem as capoeiras (gaiolas de galinhas) [...]. Estes arbustos são taquaras; toda capoeira, pois, seria um taquaral.

Faria, com o pouco siso habitual, copia essa confusão de capoeira, termo brasileiro, mato ralo e miúdo, com capoeira, termo português, jaca ou cesto fechado para conduzir galinhas. ${ }^{24}$

Como a unidade lingüística entre os países parecia abalada, os equívocos portugueses em relação ao vocabulário brasileiro eram inevitáveis. Ainda que não o fossem, Macedo Soares, provavelmente, assumiria diante deles a mesma postura de defensor incondicional dos interesses nacionais contra o "português, o pé de chumbo, o galego, o mariola, o marinheiro, o lapuz $[\ldots]]^{\prime 25}$.

\section{Uma língua ou um dialeto?}

Os modos de nomear a língua falada no Brasil também nos ajudam a reconstruir posicionamentos acerca do seu estatuto. Algumas expressões utilizadas para este fim deixam antever uma visão mais favorável à unidade lingüística luso-brasileira; outras apontam para um certo grau de diversificação e outras ainda, para a requisição de autonomia plena do brazileiro em relação ao portuguez. Mapeando esse fato, Pinto assinala que, ao longo do século,

24 Ibidem. p. 41.

25 Ibidem. p. 29. 
A designação da língua do Brasil, incerta como sua vigência, oscilava entre dialeto brasileiro (Alencar, Macedo Soares, Araripe, Romero), luso-brasileiro (Macedo Soares, Baptista Caetano, Paranhos da Silva), luso-americano (Romero) neoportuguês (Araripe), brasileiro (Macedo Soares) $[\ldots] \cdot{ }^{26}$

Nos textos lexicográficos que analisamos, já os títulos demonstram tal oscilação. Brás da Costa Rubim dá a sua obra o título de Vocabulário brazileiro e acrescenta o subtítulo para servir de complemento aos dicionários da língua portuguesa, explicando no prólogo que ela

[...] compreende um grande número de vocábulos usados no Brasil, e que se não encontram nos dicionários da nossa língua [...]. ${ }^{27}$

Embora o autor deixe claro que há uma parte do léxico total da língua de uso restrito ao Brasil e que essa parte é composta de "um grande número de vocábulos" - uma considerável divergência lexical é, portanto, reconhecida -, sua concepção é a de que a língua é a mesma aqui e em Portugal.

Beaurepaire-Rohan é ainda mais favorável à unidade. Chama sua obra de Diccionario de vocábulos brasileiros e considera que tais vocábulos recobrem campos semânticos muito específicos; basicamente, dariam conta dos nomes de lugares, tribos indígenas, plantas e animais. Sua proposta é a dicionarização dessas palavras pitorescas, cuja "etymologia é tão rica de poesia"28, com vistas a facilitar sua inclusão nos textos literários. O léxico brasileiro, dessa forma, teria como principal função tropicalizar as criações literárias, imprimir-lhes uma cor lingüística local. De fato, como atestam, entre outras, as obras de José de Alencar (1829-1877) publicadas no mesmo período ${ }^{29}$, o léxico foi uma ferramenta essencial para a impressão de brasilidade aos textos artísticos: garantia-se a cor local, sobretudo com o uso de palavras provenientes do tupinambá.

Macedo Soares intitula sua obra Diccionario brasileiro da lingua portugueza. Apesar de lermos a expressão lingua portugueza no título, o autor sinaliza, em diversas passagens desse e de outros textos, que há uma versão brasileira dela, ou pelo menos de seu léxico, que requer tratamento específico. A reconstrução de seu posicionamento, porém, não é tarefa simples, dadas as constantes reformulações a que foi submetido ao longo de

$26 C f$. PINTO, Edith Pimentel. Op. cit. p. XXXII.

27 BEAUREPAIRE-ROHAN, Henrique de. Op. cit. p. 2.

28 Ibidem. p. 2.

29 ALENCAR, José de. O guarani. São Paulo: Ática, 1995 [1857]; São Paulo: Ática, 1995 [1871]; . Ubirajara. São Paulo: Ática, 1990 [1874]. 
pelo menos 17 anos dedicados ao tratamento do tema. Os estudos lexicográficos publicados por este autor em periódicos variados entre 1874 e 1891 são, a propósito, uma fonte mais rica que os títulos e prólogos dos dicionários para a interpretação de opiniões sobre o estatuto da língua falada no Brasil. Na coletânea póstuma que reúne esses textos, pudemos contabilizar 20 maneiras diferentes (excetuando as de referência menos precisa) de nomear o português do Brasil, algumas mais e outras menos favoráveis a sua autonomia.

Os nomes do português do Brasil nos Estudos lexicográficos do dialeto brasileiro são: "dialeto brasileiro", "português do Brasil”, "linguagem nacional”, "língua brasileira", "português falado no Brasil”, "português que se fala hoje no Brasil", "luso-brasileiro", "nosso dialeto", "língua pátria", "dialeto luso-brasileiro", "português da América”, "nossa atual linguagem", "brasileiro", "língua portuguesa que se fala no Brasil", "linguagem cá da terra", "nossa língua”, “dialeto nacional”, "língua de cá”, "língua do Brasil”, "língua portuguesa falada no Brasil". Nessa listagem, como facilmente notamos, há alguns rótulos mais conciliatórios, como a língua portuguesa falada no Brasil (e suas paráfrases), o português da América, ou o português do Brasil. E há outros mais separatistas, como a língua brasileira, o brasileiro, a língua do Brasil, a nossa língua, a língua de cá, a língua pátria, o dialeto nacional e o dialeto brasileiro. Essa hesitação (lexical) - patenteada pela alternância entre os substantivos língua, linguagem e dialeto (que delimitam estruturas hierarquicamente diferenciadas) e entre os qualificadores nacional, pátria, de cá, brasileiro - sugere que tais conceitos e a sua aplicabilidade à realidade lingüística do país estavam em elaboração, ou, em outros termos, que havia uma instabilidade conceitual nos estudos dessa linha.

Sobre a oscilação entre língua, linguagem, dialeto - mais interessante do ponto de vista da depreensão do estatuto atribuído ao português do Brasil -, notamos que linguagem normalmente se aproxima dos conceitos contemporâneos de norma (tal como proposto por Coseriu), ou variante (tal como empregado em sociolingüística quantitativa). Língua, por outro lado, é uma entidade com gênio ou índole própria, autônoma em relação a outras de mesma categoria, embora não haja, também neste caso, rigorosa consistência no emprego do termo. Essa flagrante aleatoriedade de uso é reconhecida pelo próprio autor num texto em que sintetiza suas inquietações acerca do problema da língua brasileira. Publicado pela primeira vez na Revista Brasileira, em 1880, o artigo "Sobre algumas palavras africanas introduzidas no português que se fala hoje no Brasil" ${ }^{30}$ encerra

3o MACEDO SOARES, Antônio Joaquim de. Sobre algumas palavras africanas introduzidas no português que se fala hoje no Brasil. Estudos Lexicográficos do dialeto brasileiro. Op. cit. p. 44-74. 
uma reflexão sobre a questão da metalinguagem, partindo do rótulo mais recorrentemente utilizado por Macedo Soares: dialeto brasileiro. $\mathrm{O}$ autor justifica essa opção terminológica e expõe suas dúvidas a respeito de seu significado:

Temos muitas vezes, no correr deste escrito, falado em dialeto brasileiro. Cumpre observar que não apuramos o valor científico da palavra dialeto. Se entendemos por dialeto a linguagem derivada da língua geral de uma nação e particular a uma cidade ou província, o brasileiro não é dialeto do português. Por outro lado, a expressão língua brasileira nos parece demasiado pretensiosa, se se quer com ela distinguir o português falado no Brasil, modificado pelo clima, pela natureza ambiente, pela influência dos elementos africano e indiano, das relações comerciais, etc. do português falado em Portugal. Empregamos como mais modesta a outra expressão, que é ao mesmo tempo menos incorreta, e dá bem a entender que nos referimos ao movimento que visivelmente se está operando na linguagem nacional. ${ }^{31}$

A linguagem nacional não poderia ser tomada como uma simples variante regional; nesse sentido, não seria um dialeto do português. Por outro lado, as modificações por que passava ainda não autorizavam falar em língua brasileira. A expressão dialeto brasileiro, então, procurava dar conta de que havia um processo notável de diferenciação em curso. Contudo, mais relevante que o próprio termo é o raciocínio que o justifica: como se tratava de nações distintas, com climas, formação étnica, atividades distintas, era natural que o que se falasse em uma e outra se diferenciasse.

Essa perspectiva naturalista era uma das principais justificativas para se requerer uma língua ou dialeto diferenciado no Brasil: assim como do latim provieram diferentes e múltiplas línguas e dialetos, pelo fato de ele ter-se expandido por lugares com realidades distintas, também do português europeu poderia estar surgindo uma nova realidade lingüística. Tal perspectiva insinua-se na previsão de Macedo Soares em relação à independência inevitável do lexicon brasileiro até meados do século XX. Haveria uma progressão histórica irrefreável em direção a seu abrasileiramento. Lembra-nos Elia ${ }^{32}$ que essa era, em relação ao português do Brasil, a posição "da fina flor da lingüística de então: Pott, Duval, Schleicher, Rufino José Cuervo, Francisco Adolfo Coelho". Tal posição estava atrelada à concepção de língua como organismo natural, para a qual estariam previstos nascimento, desenvolvimento, multiplicação e morte.

31 Ibidem. p. 73.

32 ELIA, Sílvio Edmundo. Op. cit. p. 89. 
Os nomes da língua do Brasil não eram, como vimos, consensuais entre os diferentes autores, e nem mesmo consistentes em um deles. Tampouco o estatuto a ela atribuído. Essa indeterminação poderia estar relacionada ao fato de os estudos, não só sobre a língua, mas sobre as "coisas" brasileiras, serem ainda inaugurais.

De toda forma, se todo signo lingüístico resulta de um recorte operado na realidade objetiva a partir de um dado ponto de vista culturalmente marcado, a opção vacilante por uns e outros nomes para a língua do Brasil aponta para a existência de um debate acalorado. A reflexão sobre como denominar e a proposição de novos nomes parecem, com efeito, procedimentos mais comuns quando se identificam imprecisões, ou quando o nome usual parece não dar conta de um referente que passou a ser concebido a partir de uma nova perspectiva.

E eram múltiplas, mesmo em um único autor, as perspectivas a partir das quais a questão do estatuto do português do Brasil era proposta e avaliada.

\section{Léxico e gênio da Língua}

Nos debates acerca do estatuto do português do Brasil travados durante o século XIX, como afirmamos anteriormente, o nível lexical - não obstante ser tradicionalmente tomado como uma das partes mais maleáveis e suscetíveis a interferências exteriores de um sistema lingüístico ${ }^{33}$ funcionou como o principal fornecedor de argumentos para aqueles que reivindicaram, em diferentes graus, autonomia para o brazileiro. Em alguns casos, esse nível de articulação foi alçado ao posto de elemento diferenciador não apenas da língua, mas também do país:

[...] e, por dezenas de palavras que receberam [os guarani e os tupi] dos invasores, lhes deram milhares! São principalmente essas novidades indígenas que fazem do castelhano e do português da América uma língua assaz diferente do castelhano e do português da Europa. É por aí, mais do que pelas instituições políticas, que o Brasil e as repúblicas espanholas vão firmando sua individualidade, sua independência, sua nacionalidade. ${ }^{34}$

33 Para um histórico abrangente do tratamento desse nível de articulação no Ocidente, v., por exemplo, JOSEPH, John. Limiting the arbitrary. Linguistic naturalism and its opposites in Plato's Cratylus and the modern theories of language. Amsterdam/Philadelphia: John Benjamins, 2000.

34 MACEDO SOARES, Antônio Joaquim de. Notas à Declaración de la doctrina cristiana, manuscrito guarani. Estudos lexicográficos do dialeto brasileiro. Op. cit. p. 229, nota 44. 
A origem autóctone de muitas das palavras que constituíram o léxico nacional parecia garantir divergências suficientes entre a língua do Brasil e a de Portugal e, portanto, também entre os dois países. Para Macedo Soares, o léxico captava e exteriorizava uma diferença de visão de mundo e de contexto. E, se era assim, individualizava línguas e nações. Seria, ao mesmo tempo, fruto da diversidade (natural, social, cultural, política e étnica) e elemento (lingüístico) que a comprovava. Cumpriria, desse modo, o duplo papel de incorporar e refletir a organização de uma comunidade de falantes, bem como seu tempo e seu espaço.

Como havia diferenças marcantes entre a nação brasileira e a portuguesa - devidas ao clima, à topografia, à flora, à fauna e à constituição étnica -, Soares enxergava a inevitabilidade de termos, no Brasil, um lexicon nacional, descolado do lusitano, já na primeira metade do século $\mathrm{XX}$ :

Muitas delas ["vozes" = palavras] são comuns a Portugal e ao Brasil; algumas lá ficaram, que nunca foram aqui aceitas; outras, que entre nós se aforaram, jamais foram ouvidas em Portugal; outras, finalmente, que vieram de Portugal, passaram ou estão passando no Brasil pelas transformações dialetais que denunciam o progressivo desenvolvimento de todas as línguas. Não será ousadia afirmar que na segunda metade do século XX o léxicon brasileiro não há de ser mais o léxicon português. ${ }^{35}$

Para o autor, se em relação ao gênio (estrutura gramatical) a língua pudesse permanecer a mesma em uma e outra margem do Atlântico, no léxico concentrar-se-iam as contribuições brasileiras mais autênticas à língua de Camões. Dessas contribuições, com o tempo, poderia resultar a autonomia completa e definitiva do dialeto brasileiro. Nestes termos contraditórios, era equacionado o problema: o léxico, uma espécie de franja da língua, na medida em que não integraria o seu gênio, poderia ser empregado como suporte central de uma argumentação favorável à diversificação lingüística.

Essa observação requer dois esclarecimentos. O primeiro diz respeito ao que temos chamado de autonomia. Esse conceito deve ser nuançado, uma vez que a requisição de um estatuto autônomo para o português do Brasil não se deu sempre com a mesma ênfase e nos mesmos termos ao longo do século XIX, como a própria oscilação na metalinguagem que o descrevia parece apontar. O segundo está ligado ao papel contraditório que os defensores da autonomia atribuem ao léxico. Não o interpretamos como falha, até porque a determinação das funções desse nível de articulação da

35 Idem. Sobre algumas palavras africanas introduzidas no português que se fala no Brasil. Estudos lexicográficos do dialeto brasileiro. Op. cit. p. 72-73. 
língua configura-se, ainda hoje, como um problema teórico relevante para a lingüística ${ }^{36}$. Ao mesmo tempo periférico - uma vez que não integraria a índole da língua - e essencial - já que poderia implicar a individualização do brazileiro -, o vocabulário tornou-se o mais corriqueiro dos argumentos no debate. E, também ambiguamente, serviu a qualquer um dos lados, ou porque, para os separatistas, evidenciava a diferença, ou porque tal diferença, neste domínio da língua, não parecia tão significativa aos olhos dos continuístas ${ }^{37}$.

Aparentemente convencidos do potencial explicativo das estruturas lexicais, os estudiosos da linguagem de que tratamos propuseram a organização do nosso lexicon em dicionários e vocabulários exclusivamente nacionais, pois os habitantes do país precisavam conscientizar-se de seu modo de falar, conhecer e prestigiar "as palavras e as phrases que, originárias do Brazil, ou aqui populares, não se encontrão nos diccionarios da lingua portugueza, ou nelles vem com forma ou significação diferente" ${ }^{38}$. Eles não ignoravam outras esferas em que a diferenciação entre o português do Brasil e o europeu se dava e nem se sentiam inaptos a explorá-las de uma perspectiva científica, tal como se propuseram a fazer com o léxico ${ }^{39}$. Houve, ao que parece, uma eleição consciente desse nível como o principal fornecedor de argumentos lingüísticos. De toda forma, e qualquer que tenha sido o caso, como o dicionário é um dos pilares do saber lingüístico e instrumento fundamental para o que Auroux ${ }^{40}$ chamou de gramatização - isto é, o processo que conduz a "descrever e a instrumentar uma língua" confecção de tais obras corresponde a um impulso de legitimação do português do Brasil.

36 Mesmo módulos de um programa de investigação como o gerativista - que consolidou entre nós a visão de que é o sintático o nível de organização fundamental das línguas - reconhecem que as regras de junção de unidades requerem especificações concomitantes do léxico, já que os núcleos lexicais impõem restrições à estrutura argumental dos sintagmas que integram.

37 Cf. PINTO, Edith Pimentel. Op. cit.; CHRISTINO, Beatriz \& COELHO, Olga. Op. cit.

38 MACEDO SOARES, Antônio Joaquim de. Diccionario brasileiro da língua portuguesa. Op. cit., do pórtico da obra.

39 É, nesse sentido, relevante assinalar que os próprios autores fazem, mesmo nos dicionários, observações relativas a outros níveis lingüísticos e que importantes estudos gramaticais e filológicos distanciados do tratamento do léxico e do tema da autonomia do português do Brasil foram elaborados no período. Como exemplos desses estudos, podemos citar os que fizeram despontar as gramáticas hoje clássicas de Júlio Ribeiro (1845-1890), Maximino Maciel (1865-1923), Ernesto Carneiro Ribeiro (1839-1920), entre tantas outras. Essa produção, a propósito, permite creditar a esse período o nascimento de uma das mais fortes tradições brasileiras de estudos lingüísticos, aquela dedicada à descrição e à normatização da língua portuguesa.

40 AUROUX, Sylvain. A revolução tecnológica da gramatização. [Trad. Eni P. Orlandi]. Campinas: Editora da Unicamp, 1992.

41 Ibidem. p. 65. 


\section{Os atributos da língua}

Em alguns de seus textos, Macedo Soares dirige apelos aos literatos, aos jornalistas e aos brasileiros letrados em geral. Em sua visão, eles comporiam um grupo capaz de influenciar os destinos da língua no país: se valorizassem o brazileiro, incorporando-o ao seu trabalho e ao seu dia a dia, legitimariam o modo de falar local na escrita, contribuindo para firmar o português do Brasil como língua autônoma e de cultura:

Já tivemos ocasião de explicar o sentido em que empregamos a expressão dialeto brasileiro. Em geral, falamos esse dialeto, mas procuramos escrever um português que às vezes não é entendido, porque... digamos com franqueza: o português de Portugal não é inteiramente a língua do Brasil, e é raro escrever bem não sendo na própria língua. ${ }^{42}$

A escrita encaixaria o português do Brasil na categoria das línguas de civilização e o diferenciaria, por exemplo, das "línguas selvagens" de África e Ásia ${ }^{45}$ - ágrafas e, portanto, selvagens. A cada nação civilizada caberia uma língua com igual atributo. Daí a requisição de uma escrita brasileira, distinta da portuguesa. A língua por aqui já estaria diferenciada da portuguesa a ponto de a empregarmos de um outro modo; o que faltava era registrar essa mudança no sistema de representação escrita, que se mantinha ainda naquela "outra língua".

Quando comparada à outra língua, a do Brasil esteve sempre em vantagem: os autores condenavam, por exemplo, a corrupção causada pela pronúncia desnaturada ${ }^{44}$, sobretudo das vogais átonas, em Portugal, enquanto características fonéticas exclusivas do Brasil foram percebidas como recuperação e preservação de traços de um português antigo, genuíno. Na mesma medida, interferências do gálico no português de Portugal corresponderiam a uma deturpação, enquanto as interferências indígenas e africanas redundavam em enriquecimento, e até em embelezamento, da língua no Brasil. O dialeto brasileiro, em vista dos predicados que lhe eram atribuídos, seria novo e resultante de mistura (etno)lingüística; mas também seria puro e um guardião da tradição lingüística lusitana mais profunda, já que avesso a galicismos e outros modismos abundantes em Portugal.

$42 C f$. MACEDO SOARES, Antônio Joaquim de. Chapada, chapadão, chato, lomba, planiço, varge. Op. cit. p. 81.

43 Idem. Sobre algumas palavras africanas introduzidas no português que se fala no Brasil. Op. cit. p. 58.

44 PARANHOS DA SILVA, José Jorge. Sistema de orthographia brazileira, pelo auctor do Idioma do hodierno Portugal comparado com o do Brazil. Rio de Janeiro: Typografia de Lourenço Winte, 1880. p. XII. 
Novamente nos deparamos com a hesitação, oscilação, contradição que parece caracterizar os textos lingüísticos sob análise, permear toda a polêmica e contribuir para que ela de fato seja percebida como tal: havia pouco consenso, poucas noções compartilhadas e mesmo pouco conhecimento documentado sobre a língua e seus mecanismos de funcionamento; daí a ausência de visões uniformes e coerentes sobre ela. Ser conservadora e novidadeira, pura e mista era, precisa e contraditoriamente, o que conferia riqueza à língua cá da terra. A imagem da língua era, pois, heterogênea e complexa.

Esse movimento parece não ter sido exclusivo desse grupo, mas caracterizar também um clima de opinião. Schwarcz identifica-o em aspectos da própria organização de imagens do Segundo Império, que fundiam a cultura local a certas "tradições longínquas":

[...] que significa inventar uma corte em território americano, buscar todas as regras na mais fiel tradição medieval européia, mas adotar nomes e títulos indígenas? Como explicar um príncipe que se veste com o rigor majestático das grandes cortes, porém introduz uma murça de penas de papo de tucano, tal qual um cacique, e um manto com ramos de café e tabaco? O que dizer da famosa Fazenda de Santa Cruz, tirada dos jesuítas quando de sua expulsão pelos monarcas portugueses aqui residentes, que agrupava um número elevado de escravos-cantores de música sacra? De que maneira entender um imperador que se sentava na frente dos estandes brasileiros das exposições universais - verdadeiras festas de exibição dos feitos tecnológicos e industriais capitalistas - e exibia sua coroa ao lado de produtos indígenas e da arte popular? ${ }^{45}$

Schwarcz lida com um leque bastante amplo de aspectos e nele observa a mesma busca de síntese entre o autóctone e o alóctone, entre o local e universal, que se flagra na produção lingüística relativa ao léxico do Brasil. Ao requerer para o brasileiro o status de língua de civilização e encontrar a origem de suas singularidades nas contribuições de línguas tidas como "selvagens", ou nele destacar como qualidades aspectos criticados na língua matriz, o que se mostra com maior clareza são vontades, opiniões, preferências - traços que têm sido tradicionalmente utilizados para caracterizar descrições lingüísticas como as que selecionamos para análise.

45 SCHWARCZ, Lilia Moritz. As barbas do imperador. D. Pedro II, um monarca nos trópicos. $3^{a}$. reimpressão. São Paulo, Companhia das Letras, 1999. p. 17. 
Outros traços, como a indefinição, também podem ser reconhecidos nos textos que analisamos. Neles, não estão definidos, por exemplo, os conceitos operatórios fundamentais à discussão do estatuto da língua (tais como os de língua, dialeto, variante). Outra indefinição é a relativa ao papel do léxico nas línguas: como o vocabulário poderia particularizar línguas e nações, e, também, ao contrário disso, estar à margem do que se considerava gênio da língua, tornou-se, devido à maleabilidade, um argumento inconsistente.

Os textos que descreveram o léxico do português do Brasil durante o século XIX tiveram certa repercussão no período em que foram publicados - receptivo a idéias baseadas no conceito de nação - mas, em seguida, foram praticamente apagados dos registros historiográficos. A razão decisiva para isso parece estar nas características retóricas dessas obras, que, ao fim e ao cabo, pareciam ter ambições bem maiores do que a de apenas consignar o vocabulário local. Entre essas ambições, estariam as de proporcionar o reconhecimento da literatura brasileira, legitimar as normas lingüísticas nacionais, contribuir para a formação de uma tradição local de descrição lingüística.

\section{Impactos da lexicografia luso-bundo-americana sobre a lingüística brasileira}

Sabemos que o processo de imposição política da língua portuguesa aos habitantes do Brasil remonta pelo menos aos anos 1750, quando uma série de documentos elaborados pela administração pombalina exigiu o seu ensino e a sua utilização nos contextos oficiais. Tal medida, aliada a diversos outros reforços ao longo da história, forjou entre nós a idéia de ser o português $a$ língua do Brasil; e essa construção de uma aparente unidade lingüística contribuiu para que o conhecimento sobre os idiomas autóctones e africanos aqui utilizados fosse construído de forma fragmentada, seja em estudos autônomos, seja em trabalhos que costuram sua descrição à do português, como os de Mendonça; Silva Neto; Rodrigues, Petter ${ }^{46}$, entre outros. Um movimento semelhante pode ser observado em relação aos estudos clássicos, especialmente os das línguas latina e grega.

46 MENDONÇA, Renato. O português do Brasil. Rio de Janeiro: Civilização Brasileira, 1936. . A influência africana no português do Brasil. $4^{\mathrm{a}}$. ed. Rio de Janeiro: Civilização Brasileira, 1973. SILVA NETO, Serafim Pereira da. Introdução ao estudo da língua portuguesa no Brasil. Rio de Janeiro: INL, 1950. . História da língua portuguesa. $2^{\text {a }}$. ed. Rio de Janeiro: Livros de Portugal, 1970. RODRIGUES, Aryon. Contribuições para a etimologia dos brasileirismos. Separata da Revista de Filologia 
Se nos lembrarmos de que a eleição do português como principal objeto de análise e a adoção preferencial da perspectiva diacrônica são duas das principais características verificadas no desenvolvimento de uma tradição brasileira de estudos da linguagem até os anos $1970^{47}$, localizaremos o problema da língua brasileira - assim nomeado pelo filólogo Sílvio Edmundo Elia em 1940 - como uma das questões centrais para o entendimento de certos processos de constituição dessa tradição. Ao que parece, a reconstrução histórica do português do Brasil - tomado em relação a sua ascendência românica ou em relação ao seu contato com outras línguas configura-se como uma das questões de base para a formação de uma tradição lingüística nacional.

Contraditoriamente, porém, é provável que o próprio interesse preponderante dos lingüistas brasileiros (de hoje e de ontem) pela língua portuguesa, associado ao intuito de investigar o que particulariza o nosso falar, tenha se convertido em estímulo para o desenvolvimento da lingüística indígena e africana nos quadros acadêmicos nacionais: se a língua portuguesa aqui se diferenciava em função do contato com outras línguas, talvez fosse necessário conhecer um pouco mais sobre elas. Essa foi, por exemplo, a justificativa apresentada por Macedo Soares $^{48}$, no século XIX, e por Silva Neto em $1950^{49}$, para defender a necessidade de se estudarem tais línguas. Dessa forma, embora nem sempre a motivação para o tratamento das línguas da América e da África no país estivesse vinculada ao interesse pelo português, esse interesse pôde ser tomado como uma justificativa suficiente para tanto, dada a atmosfera acadêmica e institucional desde muito cedo marcada pela preferência por estudar a língua portuguesa em detrimento das (várias) outras línguas aqui existentes ${ }^{50}$. Se este quadro de fato assume tais tonalidades, como saldo histórico positivo da contenda em torno da natureza do português do Brasil, podemos apontar um aprofundamento paulatino dos estudos descritivos da nossa variante do português (e de suas variantes internas) - um resultado previsível - e estudos cada vez mais numerosos e verticais sobre línguas indígenas e africanas que teriam contribuído para a sua conformação - uma espécie de efeito colateral.

Portuguesa, IX, p. 1-154, 1958. PETTER, Margarida Maria Taddoni. A presença de línguas africanas no português do Brasil. Estudos Lingüisticos. XXVII, p. 777-783, 1998.

$47 C f$. levantamento e análise que ratificam esta tendência em ALTMAN, Cristina. $A$ pesquisa lingüística no Brasil (1968-1988). São Paulo, Humanitas, 1998.

48 MACEDO SOARES, Antônio Joaquim de. Estudos lexicográficos do dialeto brasileiro. Op. cit.

49 SILVA NETO, Serafim Pereira da. Op. cit.

5o A respeito da diversidade de línguas existentes no Brasil, do período colonial aos nossos dias, v. RODRIGUES, Aryon. As outras línguas da colonização do Brasil. In CARDOSO, Suzana et. al. 500 anos de história lingüistica do Brasil, 2000. 
Propomos, além disso, que essa opção pelo local (ou nacional) encontre suas raízes na concepção de língua - e de seu estudo - como parte essencial do que nos define e identifica. As abordagens contextuais, transdisciplinares e discursivas da linguagem, tão marcadamente sedutoras para o lingüista brasileiro, teriam encontrado nessa concepção um porto seguro para a sua ancoragem.

Outra característica que parece se impor aos estudos da linguagem desde esse período é sua tênue vocação para o que poderíamos rotular como empirismo. Se devemos admitir que os lexicógrafos do dialeto brasileiro utilizaram diversificadas fontes bibliográficas para a confecção dos dicionários - e essas fontes iam de textos sobre o folclore nacional a obras filológico-lingüísticas da última hora na Europa -, cumpre também admitir que raríssimas e pouco esclarecedoras referências são feitas, por exemplo, a eventuais pesquisas de campo. Isso leva a supor que, ou os procedimentos para a coleta, compilação e tratamento de dados eram largamente compartilhados - a ponto de justificar a ausência de explicitações -, ou a pesquisa bibliográfica, de gabinete, era tida como suficiente para que se arbitrasse sobre a natureza da língua e de suas variantes ${ }^{51}$.

A quase ausência de pesquisas de campo - excetuadas as realizadas por Beaurepaire-Rohan nos intervalos de suas missões militares e administrativas pelas províncias do país - parece ser a responsável por um aspecto bastante curioso da conformação desse debate durante o século XIX: a língua reivindicada, sobretudo por Macedo Soares, como autônoma, ou, pelo menos, como diferente (por Rubim e Beaurepaire-Rohan), ao final das contas, compunha-se de cerca de 2.500 palavras, quase todas restritas ao âmbito popular, familiar, regional, ou, no caso das palavras indígenas, literário.

51 Em projeto de pesquisa em desenvolvimento, dedicado ao estudo dos processos de institucionalização da área de Letras e Lingüística no Brasil, nos séculos XIX e XX, propomos que a prática de manipulação de dados provenientes de pesquisa empírica surge fora das disciplinas tradicionalmente associadas ao tratamento da linguagem. Vem da história, da geografia, da etnologia, da antropologia. A lingüística que descende diretamente da filologia e da gramática clássicas tem vocação teórica ou realiza descrições baseadas em dados "de gabinete”, isto é, em exemplos, extraídos de jornais, da literatura ou das próprias vivências lingüísticas do descritor. 


\section{Datas de recebimento e aprovação dos artigos desta edição}

Cinema = Cavação:

Cendroswald Produções Cinematográficas

Carlos Augusto Calil

Recebido em 8 de junho de 2008

Aprovado em 6 de agosto de 2008

O lobisomem entre índios e brancos:

o trabalho da imaginação no Grão-Pará no final do século XVIII

Mark Harris

Recebido em 28 de abril de 2008

Aprovado em 29 de junho de 2008

A teoria da história de Caio Prado Jr.:

dialética e sentido

Jorge Grespan

Recebido em 1 de abril de 2008

Aprovado em 2 de maio de 2008

Caio Prado Jr. e a história agrária do Brasil e do México

Guillermo Palacios

Recebido em 27 de março de 2008

Aprovado em 12 de maio de 2008

Fronteiras da desordem:

saber e ofício nas experiências de Hélio Oiticica no Morro da Mangueira e de Carlos Nelson Ferreira dos Santos em Brás de Pina

Magaly Marques Pulhez

Recebido em 17 de abril de 2008

Aprovado em 24 de junho de 2008

"O linguajar multifário":

os estrangeiros e suas línguas na ficção de Mário de Andrade

Maria Caterina Pincherle

Recebido em 20 de março de 2007

Aprovado em 6 de agosto de 2008

Os nomes da língua:

configuração e desdobramentos do debate sobre a língua brasileira no século XIX

Olga Ferreira Coelho

Recebido em 26 de maio de 2007

Aprovado em 6 de agosto de 2008

Caetés:

nossa gente é sem herói

Erwin Torralbo Gimenez

Recebido em 5 de janeiro de 2007

Aprovado em 6 de agosto de 2008 